\title{
The Impact of the Carbon Market on the Economics of CCUS
}

\author{
Jingyan $\mathrm{Ma}^{1, \mathrm{a}}$, Rong Kang ${ }^{2, \mathrm{~b}}$, Migang Dong ${ }^{3, \mathrm{c}}$ and Pual Conroyl ${ }^{4, \mathrm{~d}}$ \\ ${ }^{1}$ School of Economics \& Management, Northwest University, Xi'an, Shanxi Province, China \\ ${ }^{2}$ School of Economics \& Management, Northwest University, Xi'an, Shanxi Province, China \\ ${ }^{3}$ School of Economics \& Management, Northwest University, Xi'an, Shanxi Province, China \\ ${ }^{4}$ School of Economics \& Management, Northwest University, Xi'an, Shanxi Province, China \\ amjyfirst1993@163.com, 'bangrong@nwu.edu.cn, dongmg@163.com , 'conroypl@hotmail.com
}

Keywords: carbon market; carbon exchange prices; oil prices; CCUS

Abstract: This paper aims to explore the direct and indirect economic impacts of the establishment of a Chinese carbon exchange market on carbon capture, utilization, and storage (CCUS) projects from both the qualitative and quantitative perspectives. Using Beijing carbon exchange center and Daqing oil price data from December 18, 2013 to December 20, 2017, the correlation between carbon prices and oil prices are examined through a co-integration test, VAR model, and an impulse response function chart. In addition, the relationship between oil prices and CCUS is analyzed, and the combined results are used to determine the economic effect of carbon prices on CCUS. The results show that the carbon market not only has a direct impact on the economic viability of each specific CCUS project, but also indirectly increases the resource income of most CCUS projects through the positive influence of carbon prices on oil prices. The formation of the carbon market and the increase in the carbon price will help increase the economic benefits of CCUS projects and promote their development and application. This provides a positive incentive for the creation of a nationwide carbon market to promote the development of CCUS projects.

\section{Introduction}

Since 2013, the carbon market in China has developed rapidly. Carbon exchange centers in Beijing, Tianjin, Shanghai, Chongqing, Hubei, Guangdong, Shenzhen, and other places have all initiated transactions and, on this basis, in December 2015, China proposed launching a nationwide carbon exchange system in 2017 with a minimum threshold of 10,000 tons of standard coal per year. After the Kyoto Protocol took effect, the global carbon market expanded rapidly, and the climate change issue has become integrated in economic and political affairs around the world. The global carbon market will go beyond the oil market to become the largest energy exchange market in the future, and the participation of China is crucial.

CCUS and the carbon market are the most important elements of China's low-carbon transition over the next ten years. At present, the main impediments to the development of CCUS are high costs and financing difficulties; the ability to produce the additional energy consumed during the CCUS process; and verifying its public acceptance. It is expected that China's national carbon market, which was launched in December 2017, will meet the requirements to help China deal with the problems of global climate change and environmental governance, help achieve the country's carbon emission reduction target commitments, and further increase public awareness of the carbon emissions issue.

The literature related to the relationship between the carbon trading market and CCUS is limited. Most of the existing research focuses on the relationship between carbon trading prices and energy prices, and on technical economic analysis of CCUS. Much of the literature confirms the value of the establishment of a carbon market, the high correlation between carbon exchange prices and energy prices, and the key factors, such as energy prices, which can affect the economic viability of CCUS projects. Analyzing and drawing lessons from the international carbon market, L. Qin [1] and W. Zhou 
[2] discuss the necessity that China participate in international carbon exchanges and establish its own carbon trading market. Based on the VAR model, X. Yu [3] and S. Zhong [4] explore the interaction between domestic carbon exchange prices and oil prices, and conclude that there is a mutual influence between these elements. Maryam Al Mazrouei [5] and X. Xu [6] analyze the economic potential of $\mathrm{CO} 2$ enhanced oil production, and use models to study the economic benefits of CCUS projects under different scenarios. Overall, most foreign studies target developed countries, and their conclusions are not necessarily suitable for China's national conditions. Domestic research may still be in the early stages, and few studies have comprehensively examined the impact of the carbon market on CCUS.

This paper discusses the direct and indirect economic impacts of the establishment of China's carbon market on CCUS from both qualitative and quantitative perspectives. The direct economic impact of the link between CCUS and the carbon market is examined, and then the relationship between oil prices and the two other factors is investigated through the co-integration test, the VAR model, and an impulse response function chart, to determine the indirect impact of the carbon market on the economic viability of CCUS.

\section{The Direct Economic Impact of Carbon Market on CCUS}

Incentives are essential to promote the development of CCUS projects. For example, in the EU the downturn of the carbon market is the main reason behind the failure of many planned projects while in the US and Canada the implementation of various incentive policies, such as including CCUS in regional carbon exchange schemes, has contributed to the development of CCUS, making these countries world leaders. China can easily apply CCUS to the national carbon market to promote its development.

The carbon exchange price is created through a rationing transaction. When the carbon exchange price is higher than the price of emission reduction units, market participants are willing to purchase the emission reduction units which have been already issued in the secondary market, or engage in CDM (Clean Development Mechanism) and JI (Joint Implementation) exchanges to arbitrage or meet regulatory needs. The larger the gap, the greater the investor's revenue space will be. Then the demand for various emission reduction units will be enhanced, further promoting the development and application of new technology projects such as CCUS.

In addition, the development of the carbon market will provide more financing channels and innovative products such as carbon options, carbon futures, and bonds linked to carbon emissions. Enterprises use CCUS to hedge against carbon price volatility, improve the ability to effectively avoid operational impacts caused by carbon price fluctuations, and even arbitrage. These factors will encourage enterprises to use and increase investment in CCUS technology.

\section{The Indirect Economic Impact of the Carbon Market on CCUS}

The establishment of a carbon market will produce higher carbon prices. There is a high correlation between oil prices, carbon prices and the economic benefits for CCUS. Therefore, it is necessary to study the indirect impact of carbon prices on CCUS project economics.

The Impact of Carbon Exchange Prices on Oil Prices .In this section, the relationship between carbon prices and oil prices is analyzed through a co-integration test, the VAR model, and an impulse response function chart.

Data Selection and Unit Root Test. This analysis uses data collected from December 18, 2013 to December 20, 2017 for oil price (OP) and carbon exchange price (CP) variables. The carbon price data are Beijing carbon exchange prices [7], and oil price data are Daqing crude oil prices [8]. Beijing Environmental Exchange center has developed into one of the most important environmental centers in the country. It's trading volume ranks at the forefront of the national exchange centers and it is the first center in China that completed $100 \%$ of its annual compliance work, so its market price is nationally representative. Daqing Oilfield is the largest oil region in terms of proved reserves and annual output, which accounts for about $40 \%$ of China's crude oil production, so Daqing crude oil prices are 
representative of the overall national level of crude oil prices.

First of all, this paper will test the stationarity of oil and carbon trading prices. This article uses the augmented Dickey-Fuller (ADF) test to examine the stationarity of variables, and the test results are shown in Table 1.

Table 1 Results of Unit Roots Test

\begin{tabular}{ccccccc}
\hline variables & \multirow{2}{*}{ ADF } & \multicolumn{3}{c}{ Critical value } & Prob. & conclusion \\
\cline { 3 - 5 } & Statistics & $1 \%$ & $5 \%$ & $10 \%$ & & \\
\hline OP & -1.983609 & -2.567181 & -1.941127 & -1.616495 & 0.0453 & stationary \\
CP & -4.541043 & -3.436390 & -2.864095 & -2.568182 & 0.0002 & stationary \\
\hline
\end{tabular}

From the table it can be seen that both the oil prices and the carbon exchange prices are stationary sequences, all of which belong to the original stationary sequence. Therefore, in establishing the VAR model, the original sequence of oil prices and carbon exchange prices should be used for analysis.

Johansen Co-integration Test. According to the results of the unit root test, both the oil prices and carbon prices are original stationary sequences, which can be further tested by co-integration. The results of the co-integration test are shown in Table 2 and Table 3.

Table 2 Results of Trace Test

\begin{tabular}{|c|c|c|c|c|}
\hline Hypothesized & & Trace & 0.05 & \\
\hline No. of CE(s) & Eigenvalue & Statistic & Critical Value & Prob.** \\
\hline None $*$ & 0.027664 & 32.86473 & 15.49471 & 0.0001 \\
\hline At most 1 & 0.003390 & 3.548096 & 3.841466 & 0.0596 \\
\hline
\end{tabular}

Trace test indicates 1 cointegrating eqn(s) at the 0.05 level

* denotes rejection of the hypothesis at the 0.05 level

**MacKinnon-Haug-Michelis (1999) p-values

Table 3 Results of Max-eigenvalue Test

\begin{tabular}{|c|c|c|c|c|}
\hline Hypothesized & & Max-Eigen & 0.05 & \\
\hline No. of CE(s) & Eigenvalue & Statistic & Critical Value & Prob.** \\
\hline None $*$ & 0.027664 & 29.31663 & 14.26460 & 0.0001 \\
\hline At most 1 & 0.003390 & 3.548096 & 3.841466 & 0.0596 \\
\hline
\end{tabular}

M ax-eigenvalue test indicates 1 co-integrating eqn(s) at the 0.05 level

$*$ denotes rejection of the hypothesis at the 0.05 level

**M acKinnon-Haug-M ichelis (1999) p-values

The results of the trace test and the max-eigenvalue test indicate there is a co-integration relationship between carbon prices and oil prices, which exists at the 5\% significance level. Furthermore, an OLS regression was carried out to obtain the co-integration equation of carbon prices and oil prices, and the regression results are shown in Table 4.

Table 4 Regression Results

\begin{tabular}{|c|c|c|c|c|}
\hline Variable & Coefficient & Std. Error & t-Statistic & Prob. \\
\hline CP & 1.970503 & 0.104595 & 18.83938 & 0.0000 \\
\hline C & -40.84559 & 5.273241 & -7.745823 & 0.0000 \\
\hline R-squared & 0.253349 & F-statistic & 354.9221 \\
\hline Adjusted R-squared & 0.252635 & Prob(F-statistic) & 0.000000 \\
\hline
\end{tabular}

The regression results show that the degree of fit for the model is 0.253349 and the adjusted degree of fit is 0.252635 , indicating that carbon prices explain $25.3 \%$ of oil prices. The F-statistic is 354.9221 , the significance probability is 0 , and the $\mathrm{F}$ test is passed at the $1 \%$ level of significance, indicating that 
the overall simulation of the model is great. The co-integration equation can be determined, as follows:

$\mathrm{OP}=-40.84559+1.970503 \mathrm{CP}$

The $\mathrm{T}$ test is passed at the $1 \%$ significance level, indicating that carbon prices have a significant positive correlation with oil prices.

\section{Analysis of the VAR model.}

\section{( 1 ) Determination of Lagged Differences}

This paper determines the lags and uses the AIC and SC optimal criteria for evaluation. The lagged differences are shown in Table 5. According to the results, the criteria for AIC and SC are optimal at the same time. Therefore, a VAR (2) model should be established for the VAR model.

Table 5 Results of Lags Evaluation

\begin{tabular}{|c|c|c|c|c|c|c|}
\hline Lag & LogL & LR & FPE & AIC & SC & HQ \\
\hline 0 & -8114.592 & NA & 18836.33 & 15.51930 & 15.52877 & 15.52289 \\
\hline 1 & -4085.443 & 8035.187 & 8.561479 & 7.823027 & 7.851437 & 7.833801 \\
\hline 2 & -4067.645 & $35.42590^{*}$ & $8.338560 *$ & $7.796645^{*}$ & $7.843994 *$ & $7.814601^{*}$ \\
\hline
\end{tabular}

\section{( 2 ) Stability Test}

This article further tests the stability of the VAR model with the unit circle results shown in Figure 1. There are two endogenous variables used in this paper and two lags, so there are four characteristic roots. From the results in Figure 1, we can see that four characteristic roots lie in the unit circle, indicating that the VAR model is stable.

\section{Inverse Roots of AR Characteristic Polynomial}

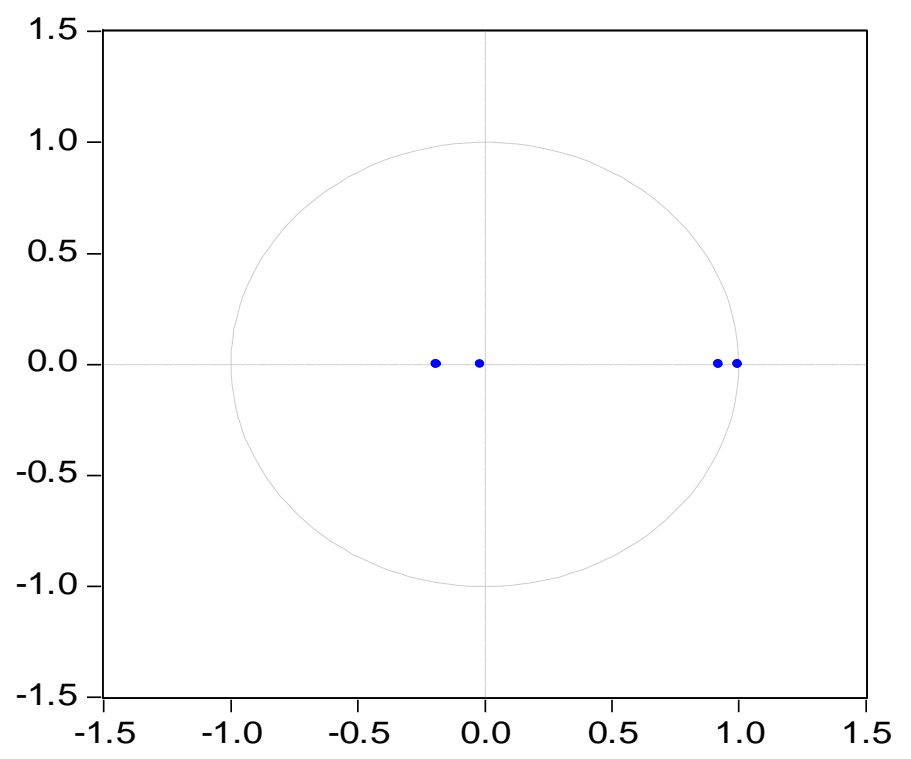

Figure1 Stability Test of VAR Test

\section{( 3 ) Analysis of Impulse Response}

The impulse response function can comprehensively reflect the dynamic impact between variables. Therefore, we analyze the impulse response of carbon prices and oil prices, and the result is shown in Figure 2. 
Response of OP to CP

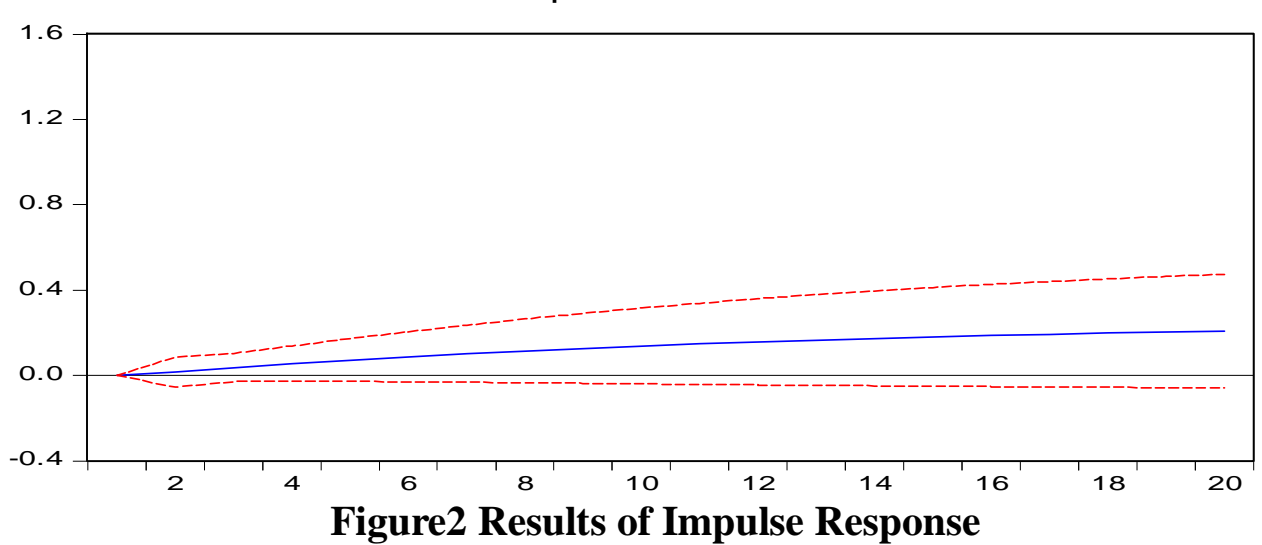

The results show that carbon exchange prices have a positive effect on oil prices in the short and long terms, which gradually increases over time. It is expected that the establishment of a nationwide carbon market will further enhance the impact of carbon trading prices on oil prices.

The economic impact of oil prices on CCUS. Empirical analysis shows that carbon exchange prices have a significant positive impact on oil prices. Due to the high correlation between oil prices and the economic viability of CCUS, we will deduce the indirect economic impact of carbon exchange prices on CCUS based on the impact of oil prices on CCUS.

In practice, CCUS utilizes the carbon dioxide emitted in standard production processes in new production processes, effectively recycling the $\mathrm{CO} 2$ rather than simply sealing it underground. Captured carbon dioxide can be reused and applied to traditional oil-displacement, coalbed methane, chemical utilization, emerging bio-utilization, mineralization and geothermal exploitation, and so on. CCUS can produce economic benefits and has many practical applications such as injecting carbon dioxide into reservoirs to enhance oil-displacement which can provide considerable social and economic benefits.

At present, most newly discovered oil reserves in China are low permeability reservoirs. Using carbon dioxide for oil displacement is a stable way to improve oil field development and guarantee the stable production of crude oil. Based on reserves of 3.5 billion tons and a recovery rate of $10 \%$, oil production is nearly 350 million tons, equivalent to a large oil field. It is estimated that by February 2017 the carbon dioxide for oil displacement project in the Daqing Hailar oilfield had an average daily gas injection of 330 tons and average daily oil production of 150 tons. In 2016, the Hailaer Oilfield injected 100,000 tons of carbon dioxide and produced 55,000 tons of crude oil, which made a significant contribution to the increase of oilfield production.

The benefits of CCUS projects include the income derived from reducing $\mathrm{CO} 2$ emissions and, due to the effective utilization of $\mathrm{CO} 2$ in the process of increasing oil production, the resulting increase in sales revenue from the additional crude oil. Therefore, the amount of revenue is closely related to the market price of crude oil. Taking the average price of Daqing Oilfield oil as USD37.56 per barrel in 2016, the price per ton is about USD260 to USD300, which means that the sales income of direct crude oil generated through carbon dioxide flooding realized an increase of USD14.3 million to USD16.5 million. It can be predicted that the benefits will be further improved when the project is scaled up. Excluding taxation and other reasonable factors, the increase in oil prices will help increase the sales revenue of additional crude oil, so as to make up for the excessive investment cost of CCUS projects, increase the economic viability of CCUS projects, and encourage further investment and development.

\section{Conclusions and Implications}

Conclusions. This paper analyzes the direct and indirect relationships between the establishment of a carbon market and the economics of CCUS through qualitative and quantitative analysis. It analyzes the dynamic relationship between carbon prices and oil prices by using a VAR model with data from 
December 18, 2013 to December 20, 2017, and describes the economic relationship between oil prices and CCUS, concluding that the establishment of a carbon market has an important impact on the economic viability of CCUS projects. There is an important link between the carbon market and CCUS. The establishment of a carbon market as an incentive policy will help to promote the development of CCUS, and price differences arising from quota transactions and derivative financial products may encourage enterprises to invest more in related technology. Furthermore, the establishment of a carbon market will lead to a higher carbon price, which will have a positive impact on the oil price. The impact will be significant, eventually increasing the profit rate for CCUS resources which will encourage increased investment and development of CCUS projects.

Implications. First, it is imperative that China participates in international carbon exchanges, establishes its own carbon market, and considers adding CCS into the carbon market. The government may consider establishing a certification mechanism for transportation, storage, and utilization of CCUS, promoting the carbon market as the core emission reduction mechanism, and using the carbon market to support the development of CCUS.

Second, the carbon market and the carbon exchange mechanism will result in higher carbon prices. However, the growth in the carbon price is a long-term process which will be balanced by coal, natural gas, and low-carbon technologies, and will accelerate the development of CCUS. Therefore, the government must coordinate this process and gradually encourage changes to drive the increase in the carbon price.

Third, cost is currently the biggest obstacle to CCUS. Due to the lack of practical experience in large-scale demonstration projects, there are significant uncertainties in the operating costs of capturing, transporting, and storing $\mathrm{CO} 2$ during the entire CCUS process. Projects can benefit from increased oil production and carbon prices, and it will be necessary to demonstrate the economic viability of any project. In addition, it will be necessary to coordinate the interests of different governments and industries, formulate technical standards and action plans, implement incentive policies, and enhance public awareness of CCUS.

\section{References}

[1] L. Qin: The Status Quo of International ETS and the Necessity for China to Participate in ETS, No.11, p. 76-78,Special Zone Economy (2012).

[2] W. Zhou and J. Zhang: Reflections on the Development Path of Chinese Carbon Market, No.03, Economy and Management (2011).

[3] X. Yu and S. jin: Analysis of Interactive Relationship between Carbon Transaction Price and Oil Price in China by VAR Model, No.03 of June, p. 259-267, Statistics and Application (2017).

[4] S. Zhong and X. Zeng, in: Impact of Carbon prices on Energy Prices and Price Fluctuation in China, No.6 of Philosophy and Social Sciences Edition, Journal of Northwest University (2014).

[5] Maryam Al Mazrouei, Omar Asad, Mohammad Abu Zahra, Toufic Mezher and I-Tsung Tsai: CO2-Enhanced Oil Recovery System Optimization for Contract-based versus Integrated Operations (2017).

[6] X. Xu, Study on Comprehensive Economic Evaluation and Indexes of CCS-EOR Whole-process Project Based on Post-combustion Capture in Coal-fired Power Plants (2016).

[7] Information on http://www.tanpaifang.com

[8] Information on http://app.finance.ifeng.com 